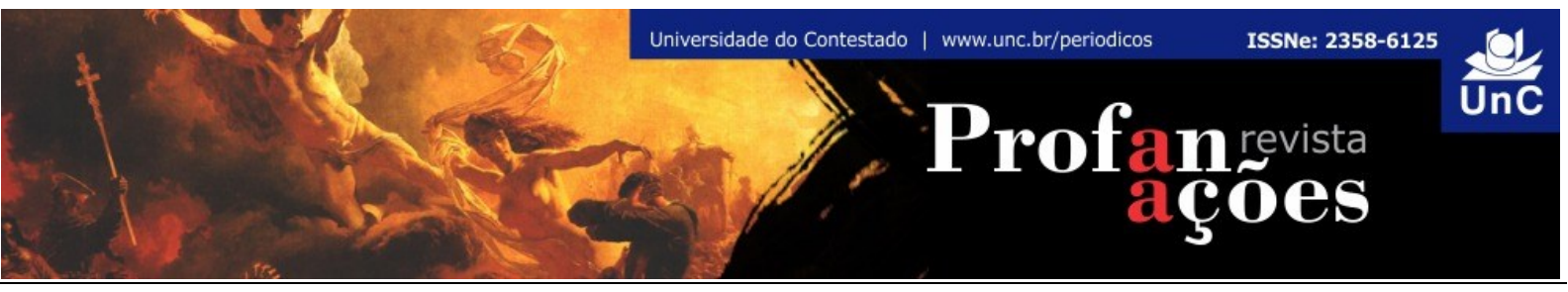

\title{
O DESEMPREGO ESTRUTURAL NO CONTEXTO DO CAPITALISMO GLOBAL CONTEMPORÂNEO À LUZ DA TEORIA DE ŽIŽEK
}

\author{
Maria Anita Lustosa ${ }^{1}$ \\ Márcia Gardênia Pires ${ }^{2}$
}

\begin{abstract}
RESUMO: O objetivo deste ensaio é analisar a situação atual do desemprego estrutural que assola a existência dos indivíduos na forma de vida contemporânea, a partir de uma abordagem que compreende tal evento como uma "catástrofe pseudonatural", em decorrência da violência constitutiva do poder sistêmico do capital, nas suas diversas formas. Podemos considerar que sob o jugo do capitalismo contemporâneo, o trabalho se realiza como experiência negativa para aqueles que trabalham. Com efeito, essa dinâmica imanente do mercado mundial capitalista transforma trabalhadores produtivos em trabalhadores descartáveis, subprodutos do sistema de mercadorias. Para tal análise, nos ancoramos nas reflexões de Žižek (2012), quando este se ocupa de uma análise crítica sobre as principais implicações desse modelo de sociedade na subjetividade humana, na atual conjuntura histórica. A metodologia que trilhamos encontra amparo no que a literatura denominada de estudo teórico-bibliográfico, no qual elegemos como aporte teórico as obras descritas, a saber: "O Ano em que sonhamos perigosamente" (2012a), "Vivendo no fim dos tempos" (2012b) e "Primeiro tragédia depois como farsa" (2011) como fontes principais de análise. Em suma podemos assegurar que no atual momento histórico o não trabalho é uma qualidade que sustenta o próprio sistema como tal, pois o que se revela é que este, além de necessitar de trabalhadores, produz um excedente, ou seja, um 'exercito de reservas' garantido pela circulação do não trabalho, o que permite a Žižek caracterizar esse "novo" desemprego estrutural como forma de exploração, uma vez que somente no capitalismo a exploração aparece de forma naturalizada.
\end{abstract}

Palavras-chave: Desemprego estrutural. Capitalismo global. Catástrofe pseudonatural.

\footnotetext{
${ }^{1}$ Graduada em filosofia pela Universidade Estadual do Ceará com mestrado e doutorado em educação brasileira na Universidade Federal do Ceará e atualmente trabalho como professora da área de política, planejamento e gestão educacional na UECE. Universidade Estadual do Ceará UECE. Brasil. E-mail: anita lustosa@hotmail.com

2Professora do Instituto Federal de Educação, Ciência e Tecnologia da Paraíba - IFPB - Campus Campina Grande. Doutora em Educação Brasileira pela Universidade Federal do Ceará (UFC). Coordenadora do Grupo de Pesquisas: "Laboratório Marxista de Pesquisas e Estudos sobre Juventude e Trabalho - LAMPEJU", vinculado ao IFPB. Instituto Federal de Educação, Ciência e Tecnologia da Paraíba - IFPB - Campus Campina Grande. Brasil. E-mail: marciagardenia@yahoo.com.br
}

Ano 4, n. 2, p. 207-218, jul./dez. 2017. 


\title{
STRUCTURAL UNEMPLOYMENT IN THE CONTEXT OF CONTEMPORARY GLOBAL CAPITALISM IN THE LIGHT OF THE ŽIŽEK THEORY
}

\begin{abstract}
This essay aims at evaluating the current situation of structural unemployment that threatens the existence of individuals, if one considers the configuration of contemporary life, from an approach that includes a major event such as a "pseudo-natural catastrophe", resulting from the ingrained violence of the systemic power of capital as it reveals itself according to its various forms. We can consider that under the yoke of contemporary capitalism, the work is done as a negative experience for those who work. Indeed, this immanent dynamics of the capitalist world market turns productive workers in disposable workers or a byproduct of a system of commodities. For this analysis, we resorted to Žižek's reflections (2012ab) when he develops a critical analysis involving major issues regarding this model of society affected by human subjectivity, in the current historical conjuncture. The methodology we tread finds support in the literature of the so-called theoretical and bibliographical study that is the main source of analysis from which we have chosen as theoretical guidance the following works: "The Year of Dreaming Dangerously" (2012a), "Living in the End Times" (2012b) and "First as Tragedy, then as Farce" (2011). In short, we can ensure that in the current moment the non-job is a feature that supports the system as such, because what it shows is that besides requiring workers, it produces a surplus, that is, a "reserve force" guaranteed by the cycling of the non-work, which led Žižek to characterize this "new" structural unemployment as a form of exploitation, since only in a capitalist configuration this kind of abuse appears as a natural human feature.
\end{abstract}

Keywords: Structural unemployment. Global capitalism. Pseudo-natural Catastrophe

\section{INTRODUÇÃO}

O objetivo deste ensaio é situar o fenômeno do desemprego, tal como ocorre na sociedade contemporânea, a partir de um enfoque que o compreende como uma forma de "violência abstrata" (ZIZEK, 2012, p. 199), que atinge bilhões de pessoas no mundo inteiro. Cumpre esclarecer que tal fenômeno é próprio de uma lógica societal, que tem no mercado o seu elemento regulador na produção de bens, riquezas e geração de lucro. Assim, quando necessário a lógica imposta por uma sociedade ditada por relações mercantis, esta torna supérflua uma grande massa desvalida de trabalhadores, que na atualidade "perambulam pelo mundo, como prometeus modernos, à cata de algo para sobreviver". (ANTUNES, 2005, p. 12-13).

Para tal análise, nos ancoramos no aporte teórico marxista e nas apreensões de Žižek (2012b), quando este se ocupa de uma análise crítica sobre as principais 
implicações desse modelo de sociedade e de sua lógica desumanizante à subjetividade humana. Este estudo bibliográfico tem como aporte teórico as obras descritas, a saber: "O Ano em que sonhamos perigosamente" (2012a), "Vivendo no fim dos tempos" (2012b), "Vidas desperdiçadas" (BAUMAM, 2005), "Lukács e o século XXI: trabalho, estranhamento e capitalismo manipulatório" (ALVES, 2010) e "O novo tempo do mundo: e outros estudos sobre a era da emergência" (ARANTES, 2014).

Partindo deste viés de análise, inferimos que no atual momento histórico, o "não trabalho" é uma qualidade que sustenta o próprio sistema como tal, produzindo um excedente de trabalhadores desempregados, na forma de desemprego estrutural (MĖSZÁROS, 2009), garantido pela circulação do não trabalho, o que permite a Žižek caracterizar esse fenômeno como mais uma forma de exploração que aparece de forma naturalizada pela lógica capitalista.

O propósito que move esta análise é reunir subsídios que colaborem para melhor elucidar a problemática crescente que vem agravando as condições existenciais dos indivíduos, expressas em formas de adoecimentos, que fragilizam as possibilidades de luta dos trabalhadores nas particularidades históricas de nosso tempo.

\section{O DESEMPREGO NO CONTEXTO DO CAPITALISMO GLOBAL CONTEMPORÂNEO}

O atual cenário social é palco para se colocar em prática as novas estratégias da dominação capitalista, expressas em artimanhas como a perda súbita de empregos que acomete os trabalhadores no capitalismo contemporâneo. Com o continuum de globalização capitalista, os trabalhadores desempregados compõem um segmento social que, no entender de Žižek (2012a, p. 11), deve ser compreendido sob uma nova denominação que não se limita à noção clássica designada por Marx (1983) de "exército industrial de reserva". Assim, referido autor reúne subsídios para elucidar o fenômeno do desemprego no atual estágio, considerando as particularidades que este assume no mundo contemporâneo. Devese sublinhar que ao direcionar seu foco de análise para a grande masssa de trabalhadores descartados pelo mercado formal de trabalho, Žižek, em uma 
compreensão ampliada do termo desempregados, atribui a estes a designação de "inempregáveis", para que se possa, assim, absorver em sua denominação as "populações maciças ao redor do mundo inteiro, que foram por assim dizer desligadas da história". (2012a, p. 14).

Em termos conceituais, a necessidade de ampliação do termo é para que se possa abranger toda uma massa de desvalidos que foram esquecidos e/ou rejeitados como casos perdidos ou terminais em todo o mundo, a partir dos projetos de modernização capitalista. Essa recategorização do desemprego feita pelo autor, passa a abranger toda uma população que vive em cortiços e/ou países inteiros, subordinados, marginal e perifericamente, ao processo capitalista global (como aqueles espaços vazios dos mapas antigos), e isto inclui até mesmo o "lumpemproletariado"3.

Essa reconfiguração do termo inempregáveis abrange as seguintes denominações: os trabalhadores, o exército de reserva dos temporariamente desempregados, os permanentemente inempregáveis e os anteriormente empregados, mas agora inempregáveis, pois, para Žižek, o quarto termo inempregáveis deveria ser ilegalmente empregáveis, pois aí estão as categorias dos que trabalham nas favelas, incluindo também distintas formas de escravidão, de trabalhadores excluídos, mas que precariamente são reincluídos no mercado mundial, com a emergência do "cogito do proletariado" (2012b).

Na sequência deste escrito trataremos sobre os dilemas postos à humanidade no contexto do capitalismo global, quando se verifica que este conforma-se na atualidade como o principal produtor de novas formas de adoecimentos, produzindo, dentre outras mazelas, ansiedades, perda de autoconfiança e muitas formas de aflições próprias de uma realidade plena de incertezas, a qual estamos submetidos no tempo presente.

\footnotetext{
${ }^{3}$ Termo utilizado por Marx na ideologia Alemã para designar uma parcela da população que vive sob condições de trabalho escravo. (MARX, 2009)
} 


\section{DESAFIOS E DILEMAS POSTOS À HUMANIDADE NO CONTEXTO DO CAPITALISMO GLOBAL: CATÁSTROFE PSEUDONATURAL E O CARÁTER TRAUMÁTICO DO COGITO DO PROLETARIADO.}

O cenário de exploração e miséria em que está inscrita a história da maioria dos trabalhadores na sociedade impõe um exame mais detido dessa realidade, de forma a contribuir com o debate sobre a subordinação e a precarização em que se insere a classe trabalhadora, haja vista a perpetuação das desigualdades na sociabilidade do capital. Assim, o legado teórico de Marx, segundo Žižek (2012b), torna-se crucial para se compreender o engendramento das contradições sociais, servindo também de fundamento para explicar o crescente fenômeno de exploração dos trabalhadores e trabalhadoras no mundo contemporâneo, fenômeno este que se acirra no capitalismo.

Corroborando com as análises que consideram a forma de organização social em que vivemos, como alicerçada na exploração do trabalho humano, destacamos aqui a categoria trabalho como ponto de partida para se pensar o desenrolar histórico da humanidade. Isto porque, como anota Marx, a história da humanidade passa obrigatoriamente pela história do trabalho. Assim, a fim de que possamos entender a natureza e a importância dessa categoria, faz-se necessário explicitar a relação entre o trabalhador e o fruto do seu trabalho, considerando as condições de realização deste na sociedade capitalista, levando em conta a noção de que tal fato não pode ser compreendido fora da esfera social que a produz. Uma vez que em sua gênese, o trabalho é fonte de mediação entre o homem e a natureza, o que para Marx é "uma lei eterna do devir humano" e, como tal, não poderá ser visto como atividade que apenas transforma a natureza, mas como atividade orientada, realizada, com um fim específico a que se destina.

No entender de Žižek (2012), em meio a um contexto social permeado por situações de instabilidade social, ocasionadas por uma crise sem precedentes, a perda de empregos, dentre outras mazelas que configuram um cenário marcado por atentados terroristas, barbárie social, fome e miséria, a realidade emblemática do desemprego na atualidade configura outro tipo de "catástrofe" que causa uma violência psicológica, trazendo múltiplas implicações para a vida dos sujeitos, destacando, em meio a um cenário de crise social sem precedentes, a emergência 
de três sujeitos que podem representar as figuras emblemáticas no tempo presente. $\mathrm{Na}$ perspectiva de análise desse autor, nosso atual tempo histórico é um momento propício à produção desses três de tipos sujeitos, vítimas dessa realidade social perversa e desumana, a saber:

\begin{abstract}
A primeira figura, que corresponde ao cercamento da natureza externa, é, talvez inesperadamente, a noção de proletário de Marx, o trabalhador explorado cujo produto é tomado dele, reduzindo-o a uma subjetividade sem substância, ao vazio da pura potencialidade subjetiva, cuja realização no processo de trabalho se iguala à sua desrealização. A segunda figura, que corresponde ao cercamento da 'segunda natureza' simbólica, é a do sujeito totalmente 'midiatizado', totalmente mergulhado na realidade virtual: embora ele pense 'espontaneamente' que está em contato direto com a realidade sua relação com a realidade é sustentada por uma complexa maquinaria digital. Podemos citar aqui Neo, o herói de Matrix, que descobre de repente que aquilo que ele percebe como realidade cotidiana é construído e manipulado por um supercomputador; sua posição não é precisamente a da vítima do malin génie cartesiano? A terceira figura, que corresponde ao cercamento de nossa natureza 'interior' é o sujeito póstraumático: se quisermos ter uma ideia do cogito em seu aspecto mais puro, de seu 'grau zero' temos de dar uma olhada nos 'monstros' autistas, um espetáculo extremamente doloroso e perturbador. É por isso que resistimos tão firmemente à visão do cogito (ŽlŽEK, 2012b, p. 219, grifos nossos)
\end{abstract}

Portanto, o autor reconhece o caráter traumático do cogito associado a estas catástrofes ambientais e sociais na figura dos refugiados dos campos de concentração, nas vítimas do terrorismo, ou mesmo nos sobreviventes de catástrofes naturais ou biológicas, além dos que sofrem situações de violência familiar. Diante disso, Žižek ao fazer referência a Malabou, assinala

[...] hoje, as vítimas de traumas sociopolíticos apresentam o mesmo perfil das vítimas de catástrofes naturais (tsunamis, terremotos, inundações) ou acidentes graves (acidentes domésticos sérios, explosões, incêndios). Começamos uma nova época de violência política, em que a política tira recursos da renúncia do sentido político da violência. [...] Todos os eventos traumatizantes tendem a neutralizar sua intenção e assumir a falta de motivação propriamente dita dos incidentes do acaso, característica essa que não pode ser interpretada. Hoje, o inimigo é a hermenêutica. [...] esse apagamento do sentido não só é perceptível nos países em guerra, como está presente em toda parte, como nova face do social que confirme uma patologia psíquica desconhecida, idêntica em todos os casos e em todos os contextos, globalizada. (MALABOU apud ŽlŽEK, 2012b, p. 202).

$\mathrm{Na}$ visão desse autor, nossa estrutura sociopolítica, além de nos impor um encontro rotineiro com esses "choques e traumas externos", nos exprime múltiplas 
formas desse tipo de interferência, descritas em situações violentas, capazes, inclusive, de destruir o tecido simbólico da identidade dos sujeitos. É Possível asseverar que, pelo viés psicanalítico de análise, a natureza desse tipo de trauma inesperado, além de ser uma intromissão violenta, se conforma em uma situação para a qual o sujeito não estava preparado, sendo inclusive impossível de reintegrála a sua psique.

Esses traumas externos, por sua vez, podem ser representados, na tessitura simbólica da realidade atual, de três formas distintas: como violência física propriamente dita, quando somos surpreendidos por ataques terroristas, em situações de violência nas ruas, estupros etc.; ao modo de uma violência "irracional (sem sentido) da base material de nossa realidade interior (tumores cerebrais, mal de Alzheimer, lesões no cérebro, etc.)" (ŽlŽEK, 2012b, p. 200). Nesses casos, para o autor, as intromissões podem ser tão violentas e catastróficas ao ponto de devastar o sujeito, mudando inclusive sua personalidade. Isto também ocorre na forma da violência simbólica, expressa na exclusão social, que atinge bilhões de pessoas, aqueles sujeitos obrigados a vivenciarem um estado persistente do trauma e para quem este se tornou um modo de viver.

Seguindo esse viés de análise, Žižek (2012b) destaca a ideia de que um sujeito que vivencia um desses encontros traumáticos de natureza diversa (social, natural, biológica ou simbólica), passa por uma transformação tão significativa, ao ponto de poder ser assemelhada a uma experiência de "morte". E por vivenciarem esse tipo de experiência, os sujeitos saem do seu "domínio psíquico propriamente dito" (2012b, p. 201), restando-Ihes somente duas escolhas: ou reintegram o choque à sua estrutura libidinal ou sucumbem à experiência do novo, fato que destrói sua identidade ao ponto de não sobrar dela nenhum resquício.

Situações traumáticas, de qualquer natureza, conduzem os sujeitos a consequências que podem ser descritas na emergência de um novo sujeito que resiste à própria morte, entendendo aqui o termo morte como uma espécie de aniquilamento da identidade simbólica. Dessa experiência, de um sujeito que sofreu esse tipo de trauma, denominado pelo autor de "sujeito pós-traumático" (20012b, p. 201) emerge outro sujeito que não tem ligação com o sujeito anterior ao trauma.

Portanto, o autor afirma não haver relação de continuidade entre o sujeito que sofreu esse tipo de trauma, “o sujeito 'pós-traumático' (a vítima de Alzheimer ou de 
outras lesões cerebrais etc.)" e sua antiga identidade, uma vez que esse novo tipo de sujeito surge com características bem específicas que podem ser descritas no entender desse mesmo autor, pela "ausência de envolvimento emocional, profunda indiferença e desapego; trata-se, de um sujeito que não está mais no mundo". (2012, p. 201)

Portanto, para Žižek, o sujeito que sobra desse processo é

[...] o sobrevivente de sua própria morte, a casca que sobra depois que ele é privado de sua substância; por isso, o matema de Lacan para o sujeito é o $\$$, o sujeito barrado. Não é que Lacan pode pensar o surgimento de um novo sujeito que sobrevive a sua morte/desintegração; para Lacan, o sujeito como tal é um 'segundo sujeito', um sobrevivente formal (a forma sobrevivente) da perda de sua substância, do X numenal que Kant chamou de 'eu ou ele ou isso (a coisa) que pensa'. (2012b, p. 213).

Podemos considerar, portanto, que o sujeito surgente, após a ferida traumática, em meio ao caos existencial, não se limita apenas à mera reprodução/mutação do antigo sujeito, produto de uma tabula rasa, uma vez que nesse processo estão inscritos resquícios de sua antiga forma de vida que sobrevive, mas que, é reintegrada e reinserida no novo contexto. É preciso levar em consideração, porém, inclusive a forma como cada pessoa reage à impossibilidade de lidar com essas feridas biológicas, uma vez que, pelo viés psicanalítico, a própria perda é constitutiva da dimensão da subjetividade, não um horizonte de ameaça destrutiva, mas como algo que está sempre acontecendo.

O sujeito da experiência psicanalítica, ao deparar com essa perda tem sensação angustiante, pois nesse momento ele vivencia uma sensação de ausência, de estranheza que não é gerada apenas pelo momento de separação do objeto, mas, justamente pela aproximação demasiada desse mesmo objeto (causa do desejo), sendo este momento, por assim dizer, ocasião constitutiva da subjetividade (ŽIŽEK, 2012b).

Žižek, ao analisar a dimensão filosófica do sujeito "pós-traumático", ou seja, de um sujeito que sobrevive à própria morte, o faz para esclarecer que esse momento no qual o sujeito parece vivenciar uma "destruição de sua identidade (narrativa)" (2012b, p. 217) configura na verdade o momento de seu nascimento.

Ao seguir as coordenadas da leitura lacaniana sobre o "sujeito póstraumático", Žižek apreende a noção de que, sendo o sujeito submetido 
rotineiramente a um trauma externo, o que resta desse sujeito é "a forma vazia do sujeito 'morto-vivo' [...], é a forma pura da subjetividade, a forma que devia estar lá" (2012b, p. 218); um tipo de sujeito que não está em lugar nenhum e, nem tampouco, pode ser representado, pois, o sujeito em seu aspecto mais elementar está na realidade 'além do inconsciente': pois é, "a forma vazia, privada até mesmo das formações inconscientes que englobam uma variedade de investimentos libidinais" (2012b, p. 217).

Como destaca Žižek, o capitalismo global conforma-se, na atualidade, como o principal produtor de novas formas de adoecimentos, que produzem ansiedades, perda de autoconfiança e autoestima, aflições próprias dessa realidade de incertezas a que estamos submetidos no tempo presente. O "desemprego estrutural" (MÉSZÁROS, 2009) que assola a existência dos indivíduos na forma de vida contemporânea, configura na atualidade uma situação que agudiza a precarização da condição material de vida e trabalho, expondo os sujeitos a novas formas de subjugação, dominação e/ou proletarização. O autor considera, portanto, a perda súbita de empregos um tipo de "catástrofe pseudonatural" (2012b, p. 199) que na atualidade causa uma violência psicológica, trazendo múltiplas implicações para a vida dos sujeitos.

Žižek nos convida a pensar no próprio sentido do possível, quando denuncia a violência constitutiva do poder sistêmico do capital em sua abordagem, as diversas formas de intromissões externas, ou seja, violências próprias do modelo social hegemônico. Em virtude da complexidade do tema, é preciso que se reflita mais diretamente sobre a condição desses sujeitos que vivem na atual conjuntura histórica, "[...] reduzidos a uma casca pós-traumática” (2012b, p. 196).

\section{À GUISA DE CONCLUSÕES}

Para concluir, salientamos que a forma de "violência abstrata" (2012b, p. 199), expressa nas atuais formas de desemprego, atingem as pessoas como uma espécie de tsunami, expondo os novos feridos a formas de subjugação, dominação e/ou proletarização próprias do sistema capitalista. Portanto, cumpre salientar que o "desemprego estrutural" se configura na atualidade como mais uma forma de 
exploração capitalista, uma vez que ao agudizar as já precárias condições de vida e trabalho, fragiliza as possibilidades de luta dos trabalhadores.

Outra observação pertinente a ser destacada é a necessidade de se repensar o conceito de exploração, com suporte numa leitura dialética. Nesse sentido, nosso autor propõe uma reviravolta nesse conceito, incluindo assim a própria negação, uma vez que explorados não são apenas aqueles que produzem ou "criam" meios para a exploração, como os trabalhadores empregados que produzem a mais-valia apropriada pelo capital, mas também os que sãos condenados a não criar, ou seja, os desempregados e inempregáveis. Dessa forma, adverte o autor, explorados não são apenas aqueles trabalhadores que produzem mais-valia, mas todo aquele que é impedido de "cair no vórtice capitalista do trabalho assalariado explorado" (ŽlŽEK, 2012a, p. 16).

Por isso, para Žižek, é preciso dar ênfase à exploração e refletir de que forma a centralidade da exploração é manifesta hoje, pois sem uma referência à economia, todas as lutas por uma mudança representam apenas reformas contingentes e atos de resistência que em nada servem para avançar na perspectiva da transformação social.

Com efeito, Žižek reconhece as estratégias do modo de organização social hegemônico, uma vez que este sistema se utiliza das ideologias do tempo presente para obscurecer e/ou naturalizar as formas de opressão consolidadas como alternativa viável ao convívio social.

Em um modelo de sociedade que se proclama pós-ideológica, a negação do conceito de ideologia nos remete inevitavelmente à aceitação tácita de que estamos mais do que nunca capturados/imbuídos, enredados por ela. No contexto do capitalismo global, a naturalização ideológica atingiu um nível sem precedentes de aceitação, fato que nos permite concordar com o autor, quando este acentua que "são raros os que ousam até sonhar sonhos utópicos sobre alternativas possíveis" (2012a, p. 71). Nesse sentido, reconhecemos que nunca foi tão urgente o pensamento de viés crítico comprometido com ideais revolucionários autênticos.

Ademais, a luta hoje por uma nova forma de sociabilidade fora dos marcos do capitalismo, ainda prima com aquelas lutas de ontem - pela certeza e possibilidade de um mundo mais igualitário e justo, ou seja, sob este aspecto, não houve mudanças significativas. Não devemos abandonar o ideal que se opõe tanto às 
formas de desumanização quanto à degradação da vida, formas estas que produzem todo tipo de injustiças atreladas ao discurso do grande mestre capital. Por essa razão, torna-se oportuno considerar os movimentos sociais e políticos que ocorrem na atualidade e que marcam a realidade social, apontando para mudanças revolucionárias.

\section{REFERÊNCIAS}

ALVES. Giovanni. Lukács e o Século XXI: Trabalho, Estranhamento e Capitalismo Manipulatório. Londrina: Práxis; Bauru: Canal 6, 2010.

ANTUNES, Ricardo. L. C. O caracol e sua concha: ensaios sobre a nova morfologia do trabalho. São Paulo: Boitempo, 2005.

ARANTES, Paulo Eduardo. O Novo Tempo do Mundo: e outros estudos sobre a era da emergência. São Paulo: Boitempo. 2014.

BAUMAN, Zygmunt. Vidas Desperdiçadas. Rio de Janeiro: Jorge Zahar. 2005.

BOTTON, Alain de. Desejo de status. Tradução de Ryta Vinagre. Rio de Janeiro: Rocco, 2005.

MARX, Karl. Manuscritos Econômico-Filosóficos. Tradução de Jesus Ranieri. São Paulo: Boitempo, 2004.

O Capital: crítica da economia política. Livro 1. O Processo de Produção do Capital. Volume I, tomos 1 e 2. Abril cultural, 1983. 2009.

.Karl; Engels, F. (2009) A ideologia alemã. Ed. Exp. Popular, São Paulo:

MÉSZÁROS, István. Para Além do Capital: rumo a uma teoria da transição. Boitempo Editorial. São Paulo. 2009.

Žižek, Slavoj. O Ano em que Sonhamos Perigosamente; tradução Rogério Bertonni. São Paulo: Boitempo Editorial, 2012a.

. Vivendo no Fim dos Tempos; tradução Maria Beatriz de Medina São Paulo, Boitempo Editorial, 2012b.

. Primeiro como Tragédia Depois Como Farsa; tradução Maria Beatriz de Medina. São Paulo: Boitempo Editorial, 2011. 
Artigo recebido em: 30/09/2017

Artigo aprovado em: 12/12/2017

Artigo publicado em: 18/12/2017 